\title{
PERUMUSAN GARIS TANGGAL KAMARIAH INTERNASIONAL BERDASARKAN KONJUNGSI
}

\section{Oleh :}

\author{
Nur Anshari*
}

\begin{abstract}
Inside knowledge more develop is following with demand periode is more develop too, Islamic Internasional Calendar become is the inevitability of concentrate Islamic date in world. Of course the problem about that will be there in a row what is the concept in use, lunar date, matla', visible or no to hilal, conjunction be valid. Necessary discourse is too long and comprehensive inside discuss formulation Internasional Islamic Calendar. That matter was needed many people dan necessary members of religious community not to avoided with develop knowledge. We hope in this paper will bring representation what the concept Internasional Islamic Calendar in discuss in agreement reached in the world
\end{abstract}

Key Words: lunar date, internasional calendar, conjunction

\section{PENDAHULUAN}

Garis tanggal Kamariah Internasional merupakan sebuah wacana dari beberapa pakar falak untuk mencoba menyeragamkan beberapa criteria bahkan metode dalam rangka menyatukan hari untuk masuknya awal bulan dalam kalender kamariah atau hijriah. Acapkali terjadi perbedaan hari masuknya awal bulan Ramadan dan Hari Raya Idul Fitri dan Idul Adha dikarenakan perbedaan kriteria awal bulan Ramadan, Syawal, dan Zulhijjah.

Ada beberapa kriteria yang muncul dan terus dipakai dalam acuan menentukan awal bulan Hijriah khususnya Ramadan, Syawal dan Zulhijjah yaitu imkānur ru'yah, wujūd al-hilāl, dan rukyah. Adapun dalam tahun Hijriah jumlah hari dalam satu bulan bisa mencapai 29 atau 30 hari. Dalam 12 bulan di kalender Hijriah terdapat 3 bulan yang penting untuk ditentukan kapan jatuhnya tanggal 1 di setiap awal bulannya. Hal ini dikarenakan adanya ibadah mahdhah yang harus dilaksanakan yakni puasa Ramadhan di setiap masuknya bulan Ramadan, kemudian ibadah shalat hari raya Idul Fitri dan Idul Adha disetiap masuknya 
bulan Syawal dan Dzulhijjah. Patutlah hal ini menjadi permasalahan yang mau tak mau harus dihadapi setiap tahunnya.

\section{DALIL SYAR'I TENTANG AWAL BULAN}

Secara garis besar, perhitungan kalender Islam dihitung berdasarkan petunjuk yang termaktub dalam firman Allah :

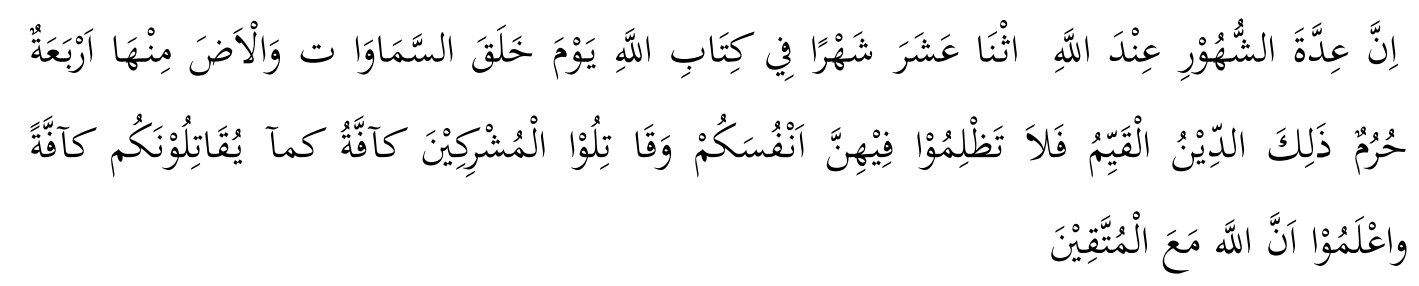

Artinya :

Sesungguhnya bilangan bulan pada sisi Allah adalah dua belas bulan, dalam ketetapan Allah di waktu Dia menciptakan langit dan bumi, di antararnya empat bulan haram. Itulah (ketetapan) agama yang lurus, maka janganlah kamu menganiaya diri kamu dalam bulan yang empat itu, dan perangilah kaum musyrikin itu semuanya sebagaimana merekapun memerangi kaтu semuanya, dan ketahuilah bahwasanya Allah beserta orang-orang yang bertakwa. (Q.S At-Taubah: 36)

Ayat diatas menjelaskan tentang Allah swt telah menetapkan satu tahun kalender terdiri dari dua belas bulan. Perhitungan awal bulan dalam kalender Hijriah dilakukan berdasarkan kedudukan bulan (hilal) dan matahari terhadap bumi. Dalam astronomi, pergantian bulan secara keseluruhan, yaitu dua belas bulan dalam satu tahun kalender dapat diketahui dan dihitung dengan mengetahui fase-fase bulan. Fase-fase bulan ini dapat diketahui karena Allah telah menetapkan keteraturan masing-masing benda langit, yaitu matahari dan bulan. ${ }^{1}$

Penerapan dan penyusunan Kalender Islam telah lama dilakukan dan digunakan oleh beberapa negara Islam. Kalender Islam dipakai secara resmi oleh negara-negara wilayah timur tengah, meskipun kebanyakan negara-negara muslim ini tetap menggunakan kalender Gregorian untuk keperluan aktifitas sosial dan kenegaraannya. Dalam hal ini, kalender Islam hanya dipakai untuk kepentingan acara yang terikat dengan prosesi keagamaan. Pengecualian adalah untuk Saudi

${ }^{1}$ Muhammad Hadi Bashori, Pengantar Ilmu Falak Pedoman Lengkap Tentang Teori dan Praktik Hisab, Arah Kiblat, Waktu Shalat, Awal Bulan Kamariah dan Gerhana, (Jakarta: Pustaka Al-Kautsar, 2005), hlm. 188 
Arabia yang saat ini merupakan satu-satunya negara di dunia yang menggunakan kalender lunar (Hijriah) untuk aktivitas resmi hariannya. ${ }^{2}$

Permasalahannya sekarang, untuk penentuan awal bulan Ramadan tidak serta merta bisa dipakai secara langsung kalender Islam yang ada selama ini. Mengapa? Sebab kalender Islam masih terbagi-bagi sesuai dengan kriteria apa dan metode apa yang diusung untuk membentuk dan menyusun kalender Islam itu. Lagi-lagi, beda metode dan kriteria kemungkinan besar bisa terjadi perbedaan. Perbedaan inilah yang mau kita hindari bila sudah komit memakai kalender Islam. Dan yang akan diusung adalah keseragaman hari dalam beribadah di seluruh dunia. Pengusungan kalender Islam global yang berlaku satu hari satu tanggal di seluruh dunia.

\section{BEBERAPA KRITERIA AWAL BULAN KAMARIAH (Wujūd al-hilāl dan Imkānur ru'yah)}

Wujūd al-hilāl Yakni teori yang menggabungkan antara sistem hisab ijtimak (qabla al-ghurūb) dan sistem imkānur ru'yah atau jalan tengah antara hisab murni dan rukyat murni. Karenanya bagi sistem wujūd al-hilāl metodologi yang dibangun dalam memulai tanggal satu bulan baru pada Kalender Hijriah tidak semata-mata proses terjadinya ijtimak tetapi juga memertimbangkan posisi hilal saat terbenam Matahari. ${ }^{3}$

Dengan kata lain teori wujūd al-hilāl berusaha memadukan tuntutan dalil Quran dan as-Sunnah. Setelah bertahun-tahun teori wujūd al-hilāl digunakan, Muhammadiyah melakukan kajian ulang agar teori yang digunakan sesuai dengan syar'i- sains dan tuntutan zaman melalui seminar dan Munas, seperti Seminar Falak Hisab Muhammadiyah tahun 1970 M/ 1390 H di Yogyakarta, Munas Tajih ke 25 pada tahun 2000 M/1421 H di Jakarta, Workshop Nasional Metodologi Penetapan Awal Bulan Qamariyah Model Muhammadiyah 2002 M/1423 H di Yogyakarta, dan Munas Tarjih ke 26 pada tahun 2003 M/1424 H di Padang. Pertemuan-pertemuan tersebut, hasilnya tetap memutuskan bahwa teori wujūd alhilāl masih relevan digunakan Muhammadiyah. ${ }^{4}$ hlm. 68

${ }^{2}$ Tono Saksono, Mengkompromikan Rukyat dan Hisab, (Jakarta: Amythas Publicita, 2007),

${ }^{3}$ Tono Saksono, Mengkompromikan, ...hlm. 68

${ }^{4}$ Ahmad Izzuddin, Fiqh Hisab Rukyah menyatukan NU dan Muhammadiyah dalam Penentuan Awal Bulan Ramadan, Idul Fitri dan Idul Adha, (Jakarta: Erlangga, 2007), hlm. 124 
Dalam rangka untuk mempersatukan hari raya ada beberapa konsep metode yang mesti dibahas yakni tentang betapapun NU tidak memiliki metode yang sama dengan pemerintah. Adapun NU memiliki metode rukyah yang tidak akan bersatu dengan metodenya pemerintah yakni imkanur rukyah yakni dengan criteria 2, 3, 8 derajat sekalipun. Adapun metode yang diusung pemerintah yakni dengan lebih dikenal imkānur ru'yah adalah sebuah criteria dimana dilakukannya hisab terlebih dahulu baru kemudian dilihat ketinggian minimum 2, 3 dan 8 derajat, dan elongasi yang tidak ketinggalan.

Adapun criteria 2,3 dan 8 derajat yang dijadikan acuan dalam kenyataannya menurut para ahli dan pemerhati astronomi tidak ilmiah dan tidak cukup kuat menjadi solusi, jika harus menerapkan 2,3,8 maka kondisi geografis-atmosfir dan luas wilayah NKRI yang demikian luas menjadi kendala. Bahkan prinsip wilayatul hukmi yang disinyalir menjadi solusi, kenyataannya juga menjadi rancu. Dengan mudah menyatakan "bila pemerintah telah menetapkan maka semua masyarakat dianjurkan mengikuti" sulit dimengerti karena selain "otoritas" yang belum kuat, ada pertentangan antara kewajiban patuh kepada ulil amri (pemerintah) dengan fakta ilmu pengetahuan yang sesungguhnya menjadi basis untuk eksisnya sebuah kalender Islam yang mapan. ${ }^{5}$

\section{KALENDER ISLAM UNIFIKATIF}

Dalam upaya merumuskan kalender Islam unifikatif harus dilakukan sinkronisasi antara zona ujung barat bumi dan zona ujung timur bumi. Wajib dijaga agar zona ujung barat tidak tertunda satu hari untuk memasuki bulan baru karena menanti zona ujung timur padahal hilal sudah dimungkinkan terlihat dengan mata telanjang secara mudah (imkanur rukyah) pada zona ujung barat itu. Sebaliknya wajib pula dijaga agar zona ujung timur tidak terpaksa memasuki bulan baru saat belum mengalami ijtimak pada hari sebelumnya karena mengikuti zona ujung barat. Untuk mempertahankan kondisi ini, maka dipegangi imkanur rukyat kategori 3 (imkanur rukyat dengan mata telanjang secara mudah dan jelas). Artinya apabila terjadi hanya rukyat kategori 2 atau 1, sementara zona ujung barat bumi belum memasuki bulan baru, maka hal ini dipandang tidak melanggar syarat validitas ke 6. Alasannya adalah pertama karena rukyat yang dimaksud dalam

${ }^{5}$ Arwin Juli Rakhmadi Butar-butar, Esai-esai Astronomi Islam, ( Medan: UMSU Press, 2015), hlm. 148 
hadis nabi saw di atas adalah rukyat yang dipraktekkan di zaman beliau, yaitu rukyat dengan mata telanjang. Ke dua apabila dipegangi rukyat kategori 2 dan 1 sebagai alat uji, maka kita tidak pernah dapat menyingkronisasikan antara ujung timur dan ujung barat bumi dalam memasuki tanggal baru, yang berarti kita tidak bisa membuat kalender global Hijriah. Ketiga, imkanur rukyat kategori 2, apabila kategori 1 adalah rukyat sukar yang tidak bisa dilakukan dengan mudah, harus ada kondisi ideal dan dilakukan oleh yang berpengalaman dengan dipandu oleh alat bantu optic, sehingga apabila tidak terlihat oleh mata telanjang dan kita belum memulai bulan baru, maka tidak melanggar hadis nabi saw di atas. Ke empat, zona dimana imkanur rukyat itu terjadi adalah di Laut pasifik di mana hanya terdapat pulau-pulau kecil dengan jumlah penduduk amat sedikit apalagi masyarakat yang beragama Islam tentu akan lebih sedikit lagi. ${ }^{6}$

Pada sisi lain apabila zona ujung barat bumi memasuki bulan baru berdasarkan imkanur rukyat kategori 2 atau 1, maka hal itu akan berakibat memaksa zona ujung timur memasuki bulan baru saat belum mengalami ijtimak pada hari sebelumnya. Ada salah satu kalender menjadikan ijtimak sebelum pukul 12:00 WU (GMT) sebagai kriterianya, atau yang lain sebelum ijtimak di titik M atau N. hal itu karena imkanur rukyat sangat relative, memiliki banyak kemungkinan dan untuk imkanur rukyat dengan alat bantu optic tergantung kepada kecanggihan alat itu. Dari apa yang dikemukakan di atas tampak dalam kalender pemersatu dengan prinsip satu hari satu tanggal di seluruh dunia, bahwa hal yang amat penting dalam upaya penyatuan kalender Islam global itu adalah bagaimana mensinkronisasikan antara zona ujung timur bumi dengan zona ujung barat bumi sehingga keduanya memasuki bulan baru pada hari yang sama secara konsisten dan tanpa terjadi pelanggaran kaidah-kaidah asasi dalam perkalenderan Islam. $^{7}$

\section{Jamaluddin Abdurraziq}

Beliau adalah salah satu ahli falak yang berasal dari kalangan penggagas penyatuan kalender Islam internasional. Ia sudah menjelaskan bagaimana konsep

\footnotetext{
${ }^{6}$ Syamsul Anwar, Diskusi dan Korespondensi Kalender Hijriah Global. (Medan: Suara Muhammadiyah, 2014), hlm. 140

${ }^{7}$ Syamsul Anwar, Diskusi dan Korespondensi,...hlm. 142
} 
kalender Islam global-nya di awal tahun 2000-an melalui buku, makalah maupun presentasi pada berbagai acara internasional yakni dalam berbagai kesempatan.

Jamaluddin yang bisa juga disebut namanya sebagai Abdurraziq pernah menuangkan dalam bukunya: at-Taqwim al-Qamari al-Islami al-Muwahhad, tahun 2004, sebagaimana diterjemahkan oleh Sofian Asma. Kalender berdasarkan bulan Kamariah atau lebih dikenal dengan Kalender Hijriah Persatuan harus memenuhi tujuh syarat berikut ini:

a. Syarat sebuah kalender, yakni memposisikan hari dalam aliran waktu yang teratur dan pasti dengan prinsip satu hari satu tanggal dan satu tanggal satu hari untuk seluruh dunia. Kalender adalah sarana untuk menentukan sebuah tanggal di suatu hari dalam satu tahun tanpa adanya kerancuan. Ini artinya bahwa sebuah kalender harus memuat pengertian kapan dan dimana sebuah hari dimulai dan berakhir. Kalender juga harus didasarkan pada perhitungan yang dapat dipakai secara mudah dan tidak dapat diintervensi oleh "pihak lain" di luar sistem yang sudah diterapkan di dalamnya.

b. Berdasarkan pada peredaran faktual bulan karena kalender ini adalah kalender qamariah. Artinya bahwa umur hari dalam satu bulan adalah 29 atau 30 hari, dan satu tahun terdiri dari 12 bulan sebagaimana ketentuan dalam surat at-Taubah: 36. Selain itu, kalender inipun harus dapat diterapkan baik untuk kepentingan sipil maupun untuk kepentingan ibadah sebagaimana petunjuk dalam surat al-Baqarah: 189

c. Bulan baru dapat dimulai apabila telah terjadi konjungsi sehingga bulan telah selesai satu putaran sinodis. Bulan qamariah tidak akan dimulai jika ada satu tempat di bumi ini yang belum mengalami konjungsi di bulan itu.

d. Syarat imkan rukyah, yaitu masuknya bulan baru hijriah yang didasarkan pada kemungkinan hilal bisa dilihat. Bulan baru hijriah tidak boleh dimulai di bagian bumi manapun tanpa adanya keyakinan bahwa hilal sudah mungkin dirukyah di belahan bumi manapun.

e. Tidak boleh menunda masuknya bulan baru ketika hilal sudah terlihat dengan mata telanjang (tanpa alat). 
f. Berlaku di seluruh dunia secara terpadu tanpa membagi bumi dalam zona-zona. Karena kalender yang ditawarkan adalah kalender unifikasi, maka harus dapat diterapkan untuk seluruh umat Islam di seluruh dunia, tidak terbatas pada dunia Islam saja karena Islam adalah agama untuk seluruh dunia yang shalih li kulli zaman wa makan. Dengan kata lain, kalender ini mampu menyatukan hari-hari besar umat Islam di seluruh dunia.

g. Bersifat global, yaitu sistem waktu yang dipakai adalah yang sejalan dengan kesepakatan dunia tentang waktu. Sistem pergantian hari pada waktu terbenam matahari (at-tauqit al-ghurubi) tidak lagi dapat diterapkan dalam kalender ini karena sifatnya yang lokal dan berubah menurut perbedaan tempat dan musim (ar-Raziq: 2006b). ${ }^{8}$

\section{Kalender Di Libia}

Perhitungan awal bulan Kamariah dalam kalender kamariah Libia menggunakan hisab hakiki dengan criteria ijtimak sebelum fajar di perbatasan sebelah timur Libia. Artinya apabila di perbatasan paling timur Libia terjadi ijtimak sebelum fajar, maka seluruh Libia memasuki bulan baru pada hari itu. Apabila di perbatasan tersebut ijtimak terjadi sesudah fajar, maka bulan kamariah baru dimulai pada fajar berikutnya. Perlu diingat bahwa kalender Libia menganut faham bahwa hari dimulai pada waktu fajar berikutnya. Perlu diingat bahwa kalender Libia menganut faham bahwa hari dimulai pada waktu fajar, bukan saat terbenamnya matahari seperti yang dianut oleh jumhur kaum Muslimin. Dalam fikih dikenal bahwa penganut faham yang memulai hari sejak terbit fajar adalah mazhab Hanafi. Meskipun umurnya berafiliasi kepada mazhab Maliki, masyarakat Muslim Libia mengikuti faham yang menjadikan permulaan hari sejak terbit fajar. $^{9}$

Dalam konteks upaya pencarian bentuk kalender Islam terpadu, para tokoh kalender. Kamariah Libia menginternasionalkan criteria bulan baru mereka (ijtimak sebelum fajar) dengan cara menarik marjak kalender dari batas timur

${ }^{8}$ Diakses pada hari Rabu, tanggal 19 Juli 2017 dengan alamat http://blog.alhabib.info/id/2016/06/kalender-hijri-persatuan-global-usulan-jamaluddin-abdurraziq/

${ }^{9}$ Syamsul Anwar, Diskusi dan Korespondensi Kalender Hijriah Global. (Medan: Suara Muhammadiyah, 2014), hlm. 15-157 
Libia ke batas paling timur bola bumi: Kiribati. Dengan demikian, rumusan kalendernya adalah apabila ijtimak terjadi sebelum fajar di titik K (Kiribati), maka seluruh dunia memasuki bulan baru pada hari itu, dan apabila ijtimak terjadi sesudah fajar di titik K, maka bulan berjalan digenapkan 30 hari dan bulan baru dimulai saat fajar berikutnya di seluruh dunia. Akan tetapi dalam perjalanan kerja, ketikaTim (Kelompok ) kerja yang dibentuk oleh Temu Pakar II melakukan uji validitas terhadap empat rancangan kalender yang diusulkan, kriteria kalender metode libia itu diperbaiki lagi dengan membuat parameter yang lebih operasional kriteria hasil perbaikan itu adalah apabila ijtimak terjadi sebelum fajar pada titik $\mathrm{M}$ dan $\mathrm{N}$ seluruh dunia memasuki bulan baru pada hari itu akan tetapi apabila ijtimak terjadi sesudah fajar di titik tersebut, maka seluruh dunia memasuki bulan baru keesokan hari. Kriteria ini lebih rumit karena selain harus menentukan saat fajar di titik $\mathrm{M}\left(60^{\circ} \mathrm{LU}\right.$ dan $\left.180^{\circ} \mathrm{BT}\right)$ pada periode musim semi dan panas di belahan bumi utara, yakni antara 20 Maret hingga 22 September, dan dititik N $\left(60^{\circ} \mathrm{LS}\right.$ dan $\left.180^{\circ} \mathrm{BT}\right)$ pada musim semi dan panas dibelahan bumi selatan, yakni antara 23 September dan 19 Maret. $^{10}$

3. Konsep Hari Universal

Mohammad Ilyas dan kelompoknya dari universitas Islam Antar Bangsa Malaysia merumuskan sebuah kriteria untuk melakukan hisab terhadap imkanur rukyat hilal (visibilitas hilal). Hasil hisab terhadap bulan dan tempat tertentu bersifat probabilitas. Dalam konteks ini dikatakan, misalnya peluang untuk melihat hilal syawal $1424 \mathrm{H}$ di kota Rabat, Maroko, pada saat terbenamnya matahari pada hari senin 24-11-2003 tidak lebih dari $20 \%$. Ini artinya bahwa kita hanya memiliki peluang $20 \%$ saja untuk dapat melihat hilal. Sebaliknya kita memiliki $80 \%$ peluang kemungkinan untuk tidak melihat hilal. ${ }^{11}$

Maka kelompok ini memilih menamakan hisab ini dengan hisab rukyat global 1 guna menunjukkan bahwa hisab ini berhasil merumuskan suatu peta dunia di mana, untuk hari tertentu terjadi perubahan peluang kemungkinan dapat merukyat hilal dari timur ke arah barat dan dari utara ke selatan. Dalam peta ini juga ditampilkan secara khusus suatu garis yang amat penting yang oleh

\footnotetext{
${ }^{10}$ Syamsul Anwar, Diskusi dan Korespondensi,..hlm. 15-157

${ }^{11}$ Jamaluddin Abd Razaq, terj. Kalender Kamariah Islam Unifikatif Satu Hari Satu Tanggal di Seluruh Dunia, (Maroko, Marsam Rabat, 2004), hlm. 26
} 
Muhammad Ilyas disebut dengan Internasional Lunar Date Line (ILDL) [Garis Tanggal Kamariah Internasional / GTKI]. ${ }^{12}$

Nama ini menunjukkan arti bahwa garis tersebut merupakan pemisah yang membagi dunia menjadi dua zona, yaitu ${ }^{13}$ :

1. Zona yang terletak disebelah barat garis dimana rukyat hilal mungkin terjadi (zona imkanur rukyat)

2. Zona yang terletak disebelah timur garis dimana tidak mungkin dilakukan rukyat hilal (zona tak dapat rukyat). Garis tanggal ini selanjutnya disebut Garis Tanggal Kalender Islam.

Maka menurut hisab ini, menurut kecenderungan yang banyak berkembang ketika melakukan perhitungan kemungkinan terjadinya rukyat hilal untuk bulan tertentu, menunjukkan hasil pokok : adanya zona imkānur ru'yah pada hari terjadinya konjungsi atau adanya zona imkanur rukyat pada keesokan hari konjungsi. Hasil hisab itu adalah terciptanya satu peta dunia dimana terdapat GTKI di samping data-data tentang umur hilal. Hisab ini juga menunjukkan lintang dan bujur titik tertentu yang kita namakan titik T ش ujung pada sisi timur GTKI. ${ }^{14}$

Adakalanya kita merasa tidak bisa mencukupkan diri dengan versi deskriptif dari hisab ini. Adapun apabila GTKI ini tetap dan tidak bergeser-geser dari satu bulan ke bulan yang lain, kita dapat memakainya seperti halnya kita memakai garis Tanggal Internasional (GTI) untuk mengubah tanggal, dan seluruh dunia dengan demikian menurut posisinya terhadap GTKI dibagi menjadi dua bagian: bagian yang memulai awal bulan baru pada hari konjungsi, dan bagian yang memulai bulan baru pada hari berikutnya. Ini sangat jauh dari kenyataan riil kita. Kalender Hijriyah Persatuan berbasis ijtima' (konjungsi) bulan telah memasuki era internasionalisasi dengan keputusan Kongres di Turki tahun 2016 ini. ${ }^{15}$

Perumusan kalender Islam Internasional dalam era global ini menemukan titik temu, dimana setiap usulan kalender mengedepankan yang namanya ijtimak (konjungsi) sebagai penanda akan dimulainya suatu proses bulan yang baru.

\footnotetext{
${ }^{12}$ Jamaluddin Abd Razaq, terj. Kalender Kamariah,..hlm. 26

${ }^{13}$ Jamaluddin Abd Razaq, terj. Kalender Kamariah,..hlm. 26

${ }^{14}$ Jamaluddin Abd Razaq, terj. Kalender Kamariah,...hlm. 27

${ }^{15}$ Jamaluddin Abd Razaq, terj. Kalender Kamariah,..hlm. 27
} 
Sudah menjadi sifatnya bumi akan terbelah menjadi dua zona yaitu pertama, zona yang mengalami ijtimak terlebih dahulu. Dan kedua zona yang mengalami ijtimak sesudah zona pertama mengalami ijtimak.

Untuk menjadikan kedua zona ini menjadi satu tanggal universal Islam tentu secara jelas kita katakan tidak akan mungkin bisa. Sementara untuk penentuan letak lunar date saja masih terjadinya simpang siur keputusan. Belum ada keputusan mutlak. Apalagi terkait dengan matla' tentu harus dilakukan penelitianpenelitian yang lebih komprehensif dan prosesnya mungkin akan memakan waktu lama.

\section{PENUTUP}

Beberapa terobosan telah menemukan titik temunya untuk mempersatukan Kalender Islam Internasional. Salah satu pakar yang ingin mencoba menemukan kalender ini adalah Muhammad Ilyas dengan konsep hisab rukyat global yang berhasil merumuskan suatu peta dunia di mana peluang kemungkinan dapat merukyat hilal dari timur ke arah barat dan dari utara ke selatan. Dalam peta ini juga ditampilkan secara khusus suatu garis yang amat penting yang oleh Muhammad Ilyas disebut dengan Internasional Lunar Date Line (ILDL) [Garis Tanggal Kamariah Internasional/GTKI]. ${ }^{16}$

Kemudian dilanjutkan dengan Negara yang bernama Libia dengan konsep hisab hakiki dengan criteria ijtimak sebelum fajar di perbatasan sebelah timur Libia. Artinya apabila di perbatasan paling timur Libia terjadi ijtimak sebelum fajar, maka seluruh Libia memasuki bulan baru pada hari itu. Apabila di perbatasan tersebut ijtimak terjadi sesudah fajar, maka bulan kamariah baru dimulai pada fajar berikutnya. Lebih mengedepankan terjadinya ijtimak (konjungsi) dalam criteria kalender Libia ini.

Tentu tidak jauh-jauh kita berbicara, bahwa diantara dua macam kalender Islam yang diusulkan diatas tentu keduanya mempunyai kelebih dan kekurangan yang sampai saat ini masih perlu diteliti dan dilakukan dirkursus ilmiah yang panjang dan komprehensif.

\footnotetext{
${ }^{16}$ Jamaluddin Abd Razaq, terj. Kalender Kamariah,..hlm. 26
} 
AL-QADHA Jurnal Hukum Islam Dan Perundang-undangan

\section{DAFTAR PUSTAKA}

Abd Razaq, Jamaluddin, terj. Kalender Kamariah Islam Unifikatif Satu Hari Satu Tanggal di Seluruh Dunia, (Maroko, Marsam Rabat, 2004)

Anwar,Syamsul, Diskusi dan Korespondensi Kalender Hijriah Global. (Medan: Suara Muhammadiyah, 2014)

Hadi Bashori, Muhammad, Pengantar Ilmu Falak Pedoman Lengkap Tentang Teori dan Praktik Hisab, Arah Kiblat, Waktu Shalat, Awal Bulan Kamariah dan Gerhana, (Jakarta: Pustaka Al-Kautsar, 2005)

http://blog.al-habib.info/id/2016/06/kalender-hijri-persatuan-global-usulan-jamaluddin-abdurraziq/

Izzuddin,Ahmad, Fiqh Hisab Rukyah menyatukan NU dan Muhammadiyah dalam Penentuan Awal Bulan Ramadan, Idul Fitri dan Idul Adha, (Jakarta: Erlangga, 2007)

Rakhmadi Butar-Butar, Arwin Juli, Esai-esai Astronomi Islam, ( Medan : UMSU Press, 2015)

Saksono,Tono, Mengkompromikan Rukyat dan Hisab, (Jakarta: Amythas Publicita, 2007) 